\title{
Strengthened Unreinforced Masonry (URM) structures with Ultra High Performance Fibre Reinforced (UHPFRC) layers under axial in-plane and horizontal out-of-plane loading
}

\author{
Andreas Lampropoulos, Ourania Tsioulou \\ School of Environment and Technology, University of Brighton, UK
}

Stephanos Dritsos

Department of Civil Engineering, University of Patras, Greece

Contact: a.lampropoulos@brighton.ac.uk

\begin{abstract}
The structural upgrade of existing Unreinforced Masonry (URM) buildings is an area with increasingly interest worldwide and especially in low-middle income countries and in earthquake prone areas. The deficiency of the existing URM has been highlighted through collapses and severe damages during recent earthquakes which could be considered as one of the greatest causes of fatalities and economic losses during major earthquakes.

The structural upgrade of existing URM has always been a quite challenging task which is mainly attributed to the relatively poor bond between the 'new' material and the existing structures. In this study a novel technique has been investigated by the addition of Ultra High Performance Fibre Reinforced Concrete (UHPFRC) layer together with partial repointing of the conventional mortar in order to increase the shear strength at the interface between masonry and UHPFRC. Numerical analyses have been conducted using Finite Element Analysis (FEA) models that have been calibrated in previous studies using experimental data for UHPFRC. Analyses have been conducted using different values for the thickness of the layer while the mortar-to-bricks and the UHPFRC-to-masonry interfaces have also been simulated. Numerical analyses have been conducted to investigate the axial in-plane and the horizontal out-of-plane behaviour of the strengthened URM specimens.

The numerical results demonstrate that the proposed technique can considerably improve the axial load strength of URM elements. In case of out-of-plane loading, the addition of UHPFRC has been proved to be quite efficient for the improvement of the stiffness and the maximum strength of existing URM structures.
\end{abstract}

Keywords: UHPFRC, masonry, strengthening, walls, axial load, out-of- plane. 


\section{Introduction}

Unreinforced Masonry (URM) is one of the most commonly used construction type in many areas worldwide including many historic and earthquake prone areas. However, the majority of these structures is characterised by very low compressive and flexural strength, especially in low and middle income countries where substandard materials are commonly used. Recent earthquakes have highlighted this deficiency of the existing URM which has resulted to significant number of fatalities and economic losses. Hence, the structural upgrade of the existing masonry structures is becoming a field of rapidly increasing importance.

The strengthening of existing URM is a quite challenging task which is mainly attributed to the low mechanical characteristics of the existing masonry and the poor bond at the interface between the 'new' strengthening materials and the existing substrate. This has been highlighted in previously published studies on the strengthening of URM structures using Fibre Reinforced Polymers (FRP) [1-4], where deficiencies related to the bond between the FRP and the existing URM have been observed. In the last few years the application of Ultra High Performance Fibre Reinforced Concrete (UHPFRC) has been examined for the strengthening of columns [5], beams $[6,7]$ and URM [8]. The efficiency of this method for the flexural strengthening of beams and columns and the improvement of the in-plane shear performance of URM walls has been highlighted through numerical analyses.

In the current study the efficiency of the addition of UHPFRC layers for the improvement of the axial in-plane and the flexural out-of-plane performance of URM walls has been examined. Finite element analyses have been conducted on specimens with various thicknesses of UHPFRC layers, while at the same time the use of UHPFRC for the partial re-pointing of the existing URM has also been examined.

\subsection{Geometry and material properties}

The geometry and the material properties of the current study are based on previous investigations
$[8,9]$. The geometry of the URM walls is illustrated in Figure 1. The width and the height of the walls have been taken equal to $120 \mathrm{~mm}$ and $450 \mathrm{~mm}$ respectively, while the thickness of the joints has been considered equal to $10 \mathrm{~mm}$. A steel plate has also been placed on the top of the examined specimens in order to ensure uniform distribution of the loads during the analyses (Figure 1).

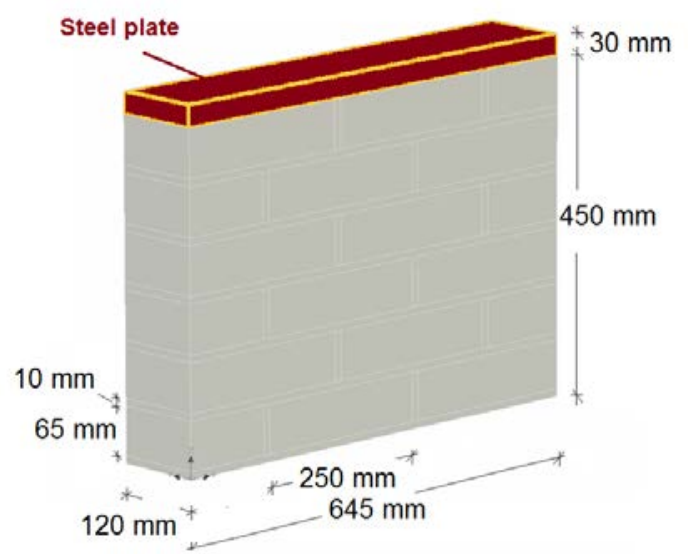

Figure 1. URM walls prior to strengthening

The use of clay bricks has been examined in this study based on previous investigations on URM $[8,9]$. The mechanical properties of both bricks and mortar are presented in Table 1.

Table 1. Mechanical properties of bricks and mortar [9]

\begin{tabular}{lcc}
\hline \multicolumn{3}{c}{ Mechanical Properties } \\
\hline & Bricks & Mortar \\
\hline Elastic modulus & 2400 & 2200 \\
(MPa) & & \\
Poisson's ratio & 0.2 & 0.2 \\
$\begin{array}{l}\text { Tensile strength } \\
\text { (MPa) }\end{array}$ & 3.4 & 0.7 \\
$\begin{array}{l}\text { Compressive } \\
\text { strength (MPa) }\end{array}$ & 18.7 & 5 \\
\hline
\end{tabular}

For the strengthening of the URM, UHPFRC layers have been applied (Figure 2). 


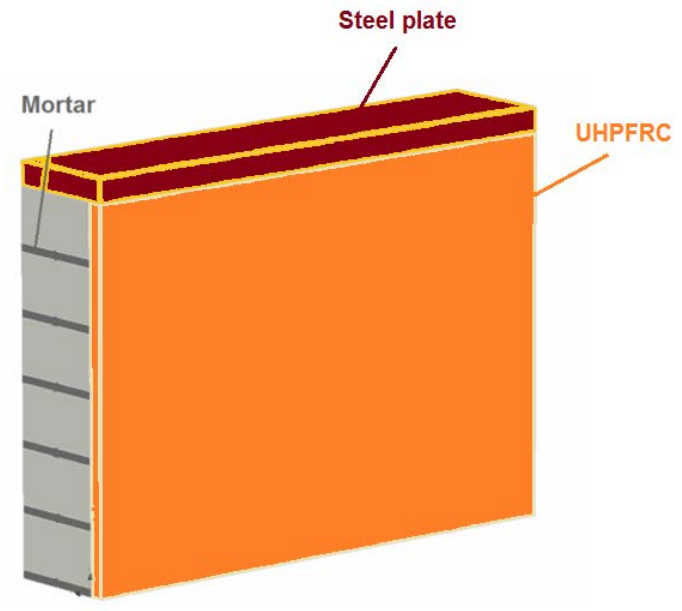

Figure 2. Strengthened URM walls with UHPFRC layers

Three different thicknesses of the UHPFRC layer have been examined; $10 \mathrm{~mm}, 20 \mathrm{~mm}$ and $30 \mathrm{~mm}$. Also, in case of strengthened walls with $20 \mathrm{~mm}$ layer, partial re-pointing of the existing conventional mortar joints with UHPFRC at half of the thickness of the walls has been examined in addition to the UHPFRC layer. These specimens have been examined in order to investigate the beneficial effect of this technique on the masonryto-UHPFRC interface (Figure 3).

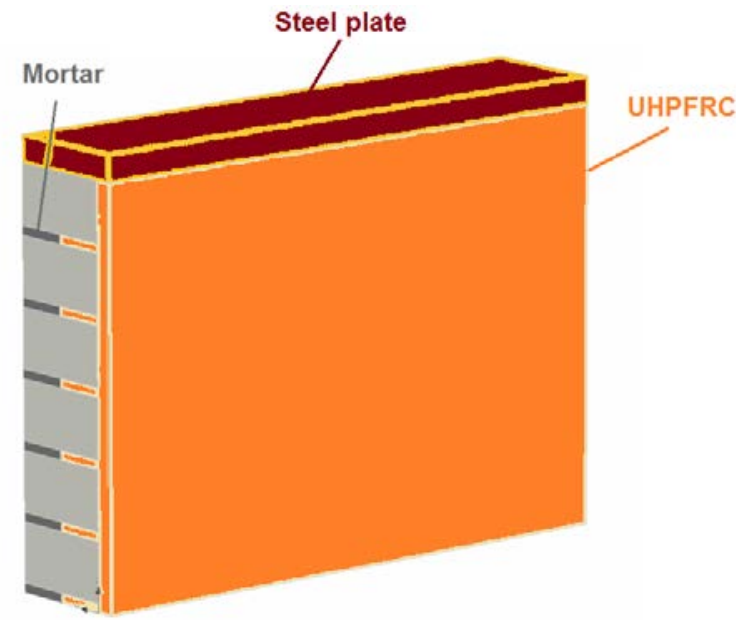

Figure 3. Strengthened URM walls with UHPFRC layers and re-pointing with UHPFRC

The mechanical properties of the UHPFRC that have been used in this investigation are based on compressive and direct tensile experimental results of a previous study [7]. Based on these results [7], the compressive and tensile strength have been taken equal to $164 \mathrm{MPa}$ and $11.5 \mathrm{MPa}$ respectively, while the modulus of Elasticity has been considered equal to $57.5 \mathrm{GPa}$.

\subsection{Numerical assumptions and results}

In this section the numerical assumptions of the finite element models are presented followed by the results of the analyses.

\subsubsection{Numerical assumptions}

ATENA Finite Element Analysis software [10] has been used in this study. For the simulation of bricks, mortar and UHPFRC, '3D nonlinear cementitious' material has been used, while '3D Elastic Isotropic' material has been used for the steel plate on the top of the specimens where the load is applied. The mechanical properties presented in Table 1 have been adopted for the bricks and the mortar, while for the steel plate Young's modulus equal to $210 \mathrm{GPa}$ has been considered. For the UHPFRC, the mechanical properties presented in section 1.1 have been used [7]. The tensile stress-strain model which has been adopted for the numerical analyses of this study for characteristic size equal to $2 \mathrm{~mm}$, consists of three linear parts after the end of the elastic part [7] (Figure 4).

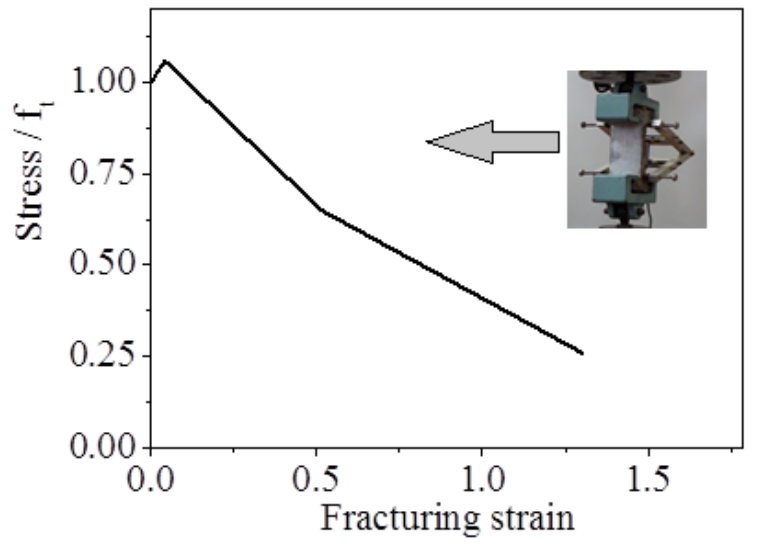

Figure 4. Tensile stress-strain model adopted for the numerical modeling of UHPFRC [7]

The numerical assumptions used in this study for the simulation of the UHPFRC (Figure 4) have been 
calibrated and validated in previous investigation using experimental data [7].

The interface between mortar/UHPFRC and bricks has also been modeled using two dimensional contact elements. For the simulation of the behaviour of the interface, coefficient of friction $(\mu)$ equal to 0.6 , cohesion equal to $0.9 \mathrm{MPa}$, and normal and tangential stiffness equal to $1 \mathrm{MPa}$ and $0.5 \mathrm{MPa}$ respectively have been used. These values are based on a previous investigation on brickwork masonry [11]. It should be mentioned that further experimental investigation is required in order to determine realistic values for UHPFRCto-bricks interface characteristics.

Two different loading conditions have been examined in the current study, axial in-plane (Figure 5a) and horizontal out-of-plane (Figure $5 b)$.

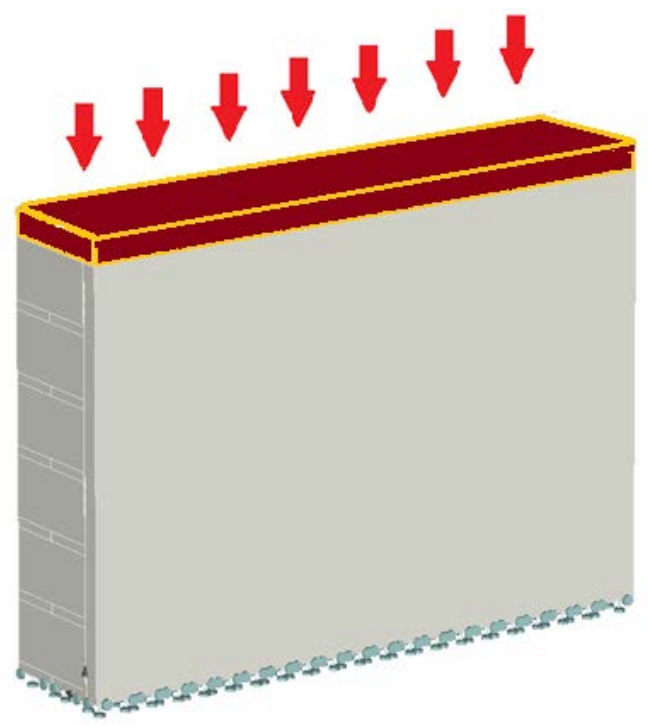

(a)

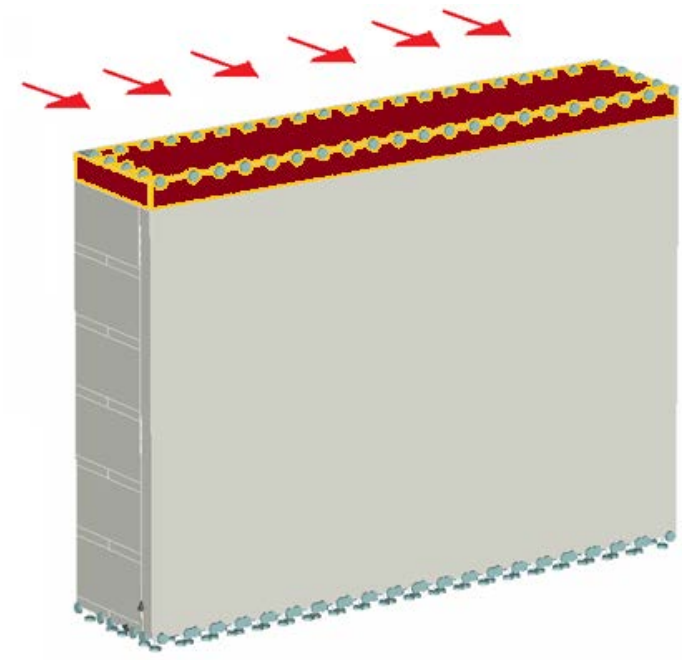

(b)

Figure 5. Loading conditions: a) axial in-plane and b) horizontal out-of-plane

In all the examined cases, the base of the specimens has been fully fixed and an incremental displacement has been applied to the steel plate at the top of the specimens. For out-of-plane loading, additional restraints have been imposed at the top of the specimens in order to avoid any vertical movement (Figure 5b).

For in-plane loading of the control URM specimen, simplified assumption of perfect bond between mortar and bricks has been considered (URM_IP). For all the strengthened specimens under axial inplane loading, contact elements have been used at the mortar-to-brick, UHPFRC-to-brick and UHPFRC-to-mortar interfaces with the properties described in section 1.2.1. Strengthened URM with $20 \mathrm{~mm}$ (URM \& $20 \mathrm{~mm}$ UHPFRC_IP), $30 \mathrm{~mm}$ (URM \& 30mm UHPFRC_IP), and $40 \mathrm{~mm}$ (URM \& $40 \mathrm{~mm}$ UHPFRC_IP) thick UHPFRC layers have been examined. Also, for the specimen with $20 \mathrm{~mm}$ UHPFRC layer, an additional specimen with UHPFRC at half of the joints' thickness in addition to the UHPFRC layer (Figure 3 ) has been examined (URM re-pointing \& 20mm UHPFRC_IP). The same assumptions have also been examined for out-ofplane loading for $20 \mathrm{~mm}$ (URM \& $20 \mathrm{~mm}$ UHPFRC_OP), $30 \mathrm{~mm}$ (URM \& $30 \mathrm{~mm}$ UHPFRC_OP), and $40 \mathrm{~mm}$ (URM \& $40 \mathrm{~mm}$ UHPFRC_OP) thick UHPFRC layers and for the specimen with $20 \mathrm{~mm}$ UHPFRC layer and UHPFRC 
at the joints (URM re-pointing \& $20 \mathrm{~mm}$ UHPFRC_OP).

The results of the analyses are presented in the following sections.

\subsubsection{Axial in-plane loading}

The load deflection results of the analyses under axial loading are presented in Figure 6.

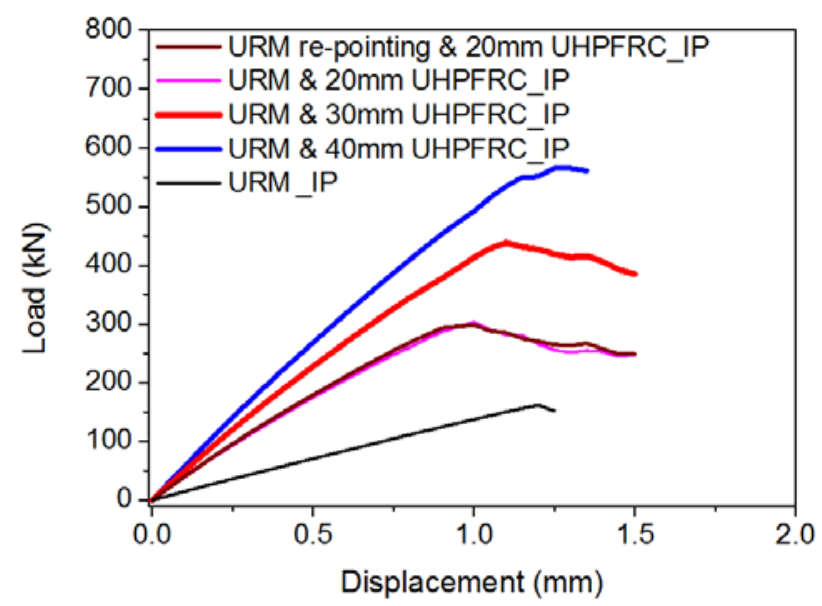

Figure 6. Load-displacement results for axial inplane loading

From the results of Figure 6 , it is evident that the addition of UHPFRC layers can considerably improve the maximum axial load strength and as expected, the contribution is increased as the thickness of the layer is increased. The maximum axial load for URM has been found equal to 161 $\mathrm{kN}$; while for $20 \mathrm{~mm}, 30 \mathrm{~mm}$ and $40 \mathrm{~mm}$ additional UHPFRC layers, the respective axial strength has been found equal to $303 \mathrm{kN}, 438 \mathrm{kN}$ and $565 \mathrm{kN}$ respectively.

It is also evident that the addition of UHPFRC at the joints, in case of specimen strengthened with $20 \mathrm{~mm}$ layer (URM re-pointing \& $20 \mathrm{~mm}$ UHPFRC_IP), has not considerably affected the load-deflection results. This is attributed to the fact that, under these loading conditions, the behaviour of the interface is not crucial.

The maximum load increment (\%) is illustrated in Figure 7.

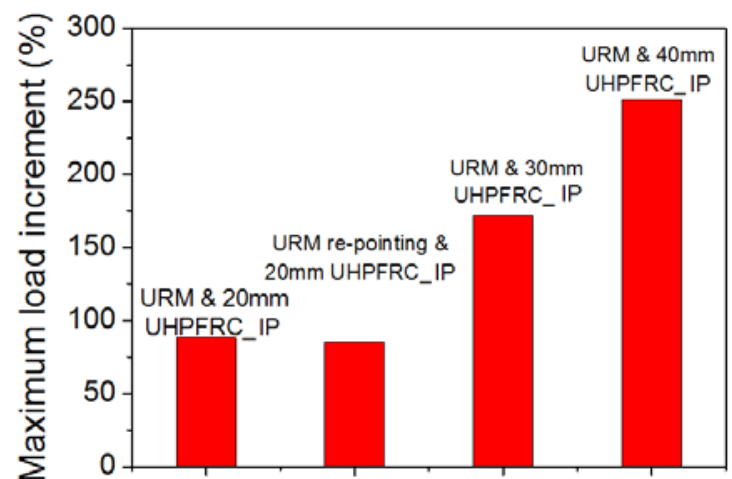

Figure 7. Maximum load increment (\%) for inplane axial loading

The results of Figure 7 indicate that substantial maximum load increments can be achieved by the addition of UHPFRC, since in the examined cases increment values in the range of $85-251 \%$ have been observed. As expected, the load enhancement is considerably increased as the thickness of the layer is increased.

The distribution of the slip at the interface of both specimens with (URM re-pointing \& $20 \mathrm{~mm}$ UHPFRC_IP) and without (URM \& $20 \mathrm{~mm}$ UHPFRC_IP) UHPFRC at the joints for displacement equal to $1 \mathrm{~mm}$, which is the displacement at the peak load, is illustrated in Figure 8 .

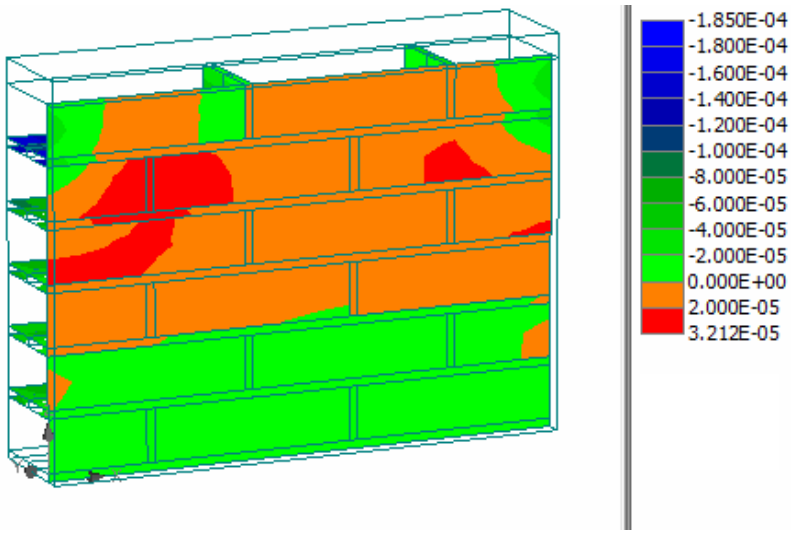

(a) 


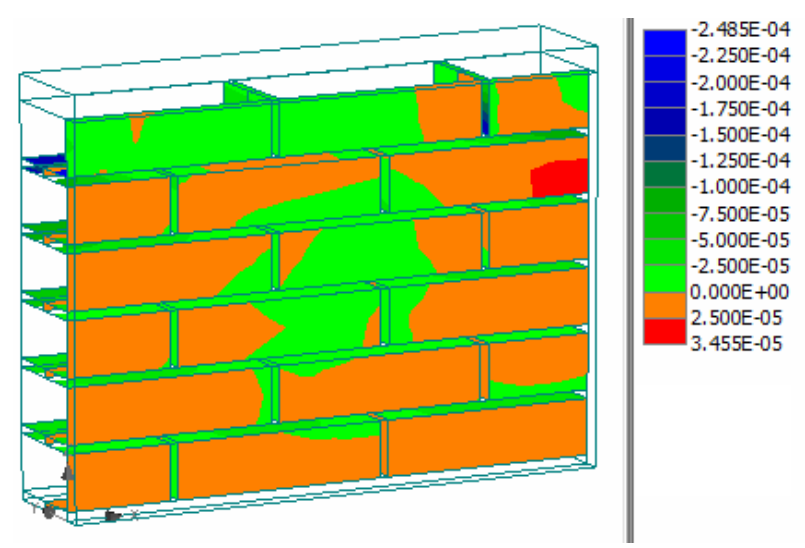

(b)

Figure 8. Slip distribution along the interface for 1 $\mathrm{mm}$ top displacement for a) URM \& $20 \mathrm{~mm}$ UHPFRC_IP and b) URM repointing \& 20mm UHPFRC_IP specimens

From the results of Figure 8 , it can be observed that there is a change in the distribution of the slip values at the interface but the maximum obtained values are not considerably affected by the addition of UHPFRC to the joints.

\subsubsection{Horizontal out-of-plane loading}

The load-deflection results for out-of-plane loading of the examined specimens are presented in Figure 9.

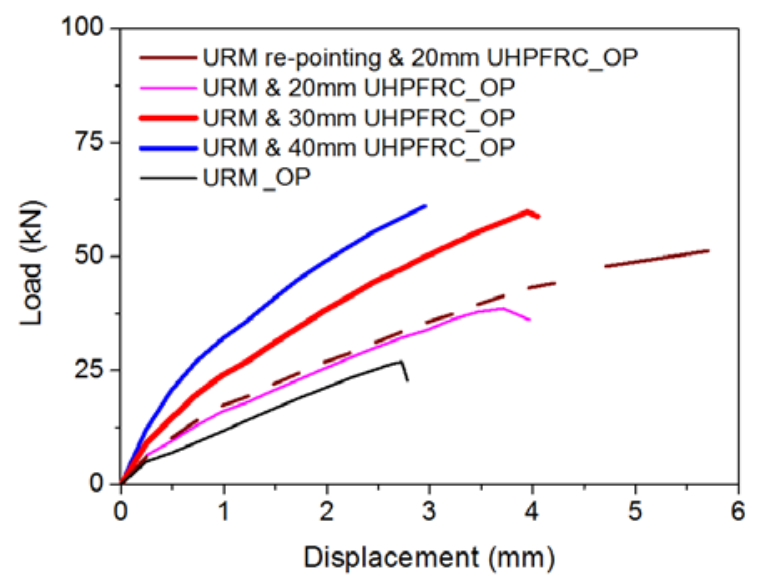

Figure 9. Load-displacement results for out-ofplane loading

The results of Figure 9 indicate that the addition of UHPFRC layers leads to significant improvement of the out-of-plane stiffness and maximum load of the URM specimens. The examined control specimen (URM) has been found to have a maximum load of almost $27 \mathrm{kN}$. Addition of 20 $\mathrm{mm}$ (URM \& 20mm UHPFRC_OP), $30 \mathrm{~mm}$ (URM \& $30 \mathrm{~mm}$ UHPFRC_OP) and $40 \mathrm{~mm}$ (URM \& $40 \mathrm{~mm}$ UHPFRC_OP) thick UHPFRC layers has resulted to increment of the maximum load to almost $39 \mathrm{kN}$, $60 \mathrm{kN}$ and $61 \mathrm{kN}$ respectively. It can also be observed that the stiffness of the examined specimens is increased as the thickness of the UHPFRC layer is increased. In case of strengthened URM with $40 \mathrm{~mm}$ thick UHPFRC layer (URM \& 40mm UHPFRC_OP), the failure of the examined specimen has been found to be concentrated on the elements of the existing URM walls which is attributed to the superior mechanical properties of UHPFRC and the high thickness of the layer. Regarding the specimen with $20 \mathrm{~mm}$ UHPFRC layer and UHPFRC at the joints (URM re-pointing \& $20 \mathrm{~mm}$ UHPFRC_OP), addition of UHPFRC to the joints leads to further increment of the load to $51.24 \mathrm{kN}$, value quite higher compared to the respective maximum load for the specimen without UHPFRC at the joints (URM \& $20 \mathrm{~mm}$ UHPFRC_OP), which has been found equal to 39 $\mathrm{kN}$.

The maximum load increments (\%) for the specimens under out-of-plane loading are presented in Figure 10.

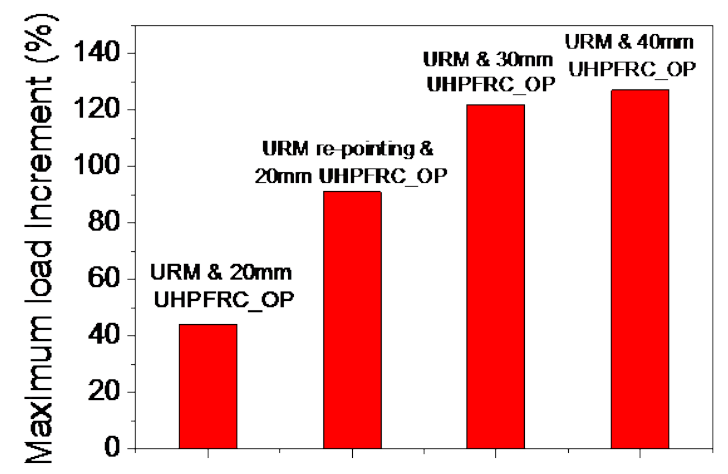

Figure 10. Maximum load increment (\%) for horizontal out-of-plane loading

Based on the results of Figure 10, the maximum load increment for out-of-plane loading of strengthened URM has been found in the range of 44-127\%. The maximum load is considerably 
increased as the thickness is increased from 20 $\mathrm{mm}$ to $30 \mathrm{~mm}$. Further increment of the layer's thickness to $40 \mathrm{~mm}$ has resulted to significant enhancement of the stiffness but the maximum load has not been significantly increased. This is attributed to the fact that in this case (URM \& 40mm UHPFRC_OP) failure has been observed mainly to the elements of the initial URM wall.

The slip at the interface for both specimens ('URM \& 20mm UHPFRC_OP', and 'URM re-pointing \& $20 \mathrm{~mm}$ UHPFRC_OP') for top displacement equal to $3.7 \mathrm{~mm}$, which corresponds to the maximum strength value for 'URM \& $20 \mathrm{~mm}$ UHPFRC_OP' specimen, is illustrated in Figure 11.

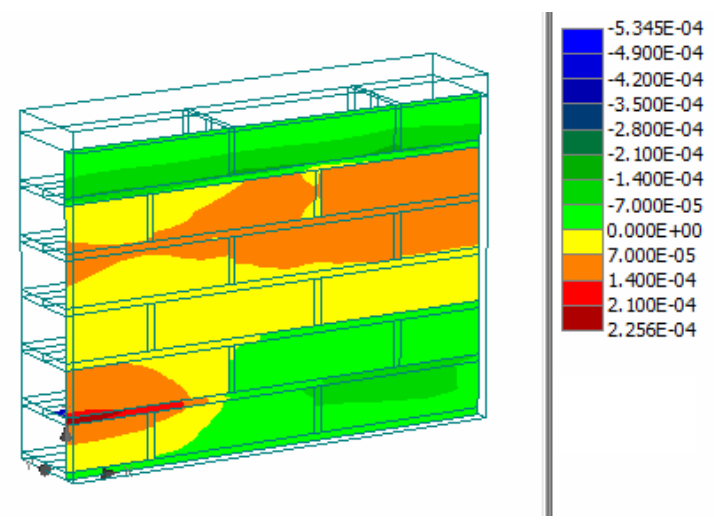

(a)

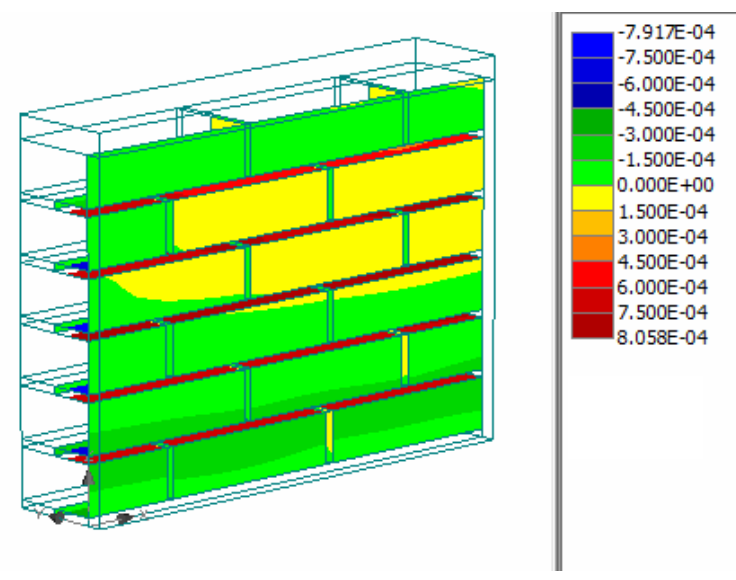

(b)

Figure 11. Slip distribution at the interface for 3.7 $\mathrm{mm}$ top displacement for a) 'URM \& $20 \mathrm{~mm}$ UHPFRC_OP' and b) 'URM repointing \& $20 \mathrm{~mm}$ UHPFR_OP' specimens
The results of Figure 11 indicate that the addition of UHPFRC at the joints (URM re-pointing \& $20 \mathrm{~mm}$ UHPFRC_OP) leads to overall significant reduction of the slip values which are mainly concentrated to a relatively small part of the interface (Figure $11 b)$, as opposed to the respective results of 'URM \& 20mm UHPFRC_OP' specimen where quite higher slip values have been observed.

\section{Conclusions}

In the current study the axial in-plane and the horizontal out-of-plane performance of URM walls strengthened with UHPFRC layers have been examined. Numerical analyses have been conducted and various thicknesses of the additional UHPFRC layer have been examined.

Based on the results of this study, the following conclusions can be drawn:

- The addition of UHPFRC layers can considerably improve the maximum axial load strength, since maximum load increment in the range of $82-251 \%$ has been achieved for UHPFRC layers with thickness 20-40 mm.

- The specimen with UHPFRC at the joints in addition to the UHPFRC layer has been found to have almost the same behaviour under axial loading with the respective specimen with conventional mortar at the joints.

- In case of out-of-plane loading, maximum load increment in the range of 44-127\% has been achieved by the addition of UHPFRC layers with thicknesses in the range of 20-40 mm. Stiffness and maximum load have been considerably increased as the thickness of the layer has been increased from $20 \mathrm{~mm}$ to $30 \mathrm{~mm}$. Increment of the thickness of the layer to $40 \mathrm{~mm}$ has resulted to further enhancement of the stiffness but the maximum load has not been significantly increased, since in this case failure has been mainly observed at the URM elements.

- In case of out-of-plane loading, addition of UHPFRC at the joints has resulted to substantial overall reduction of the 
interface slip, and subsequently higher maximum load values.

The findings of the current study indicate that the addition of UHPFRC can considerably improve the axial in-plane and horizontal out-of-plane performance of URM. However, it should be mentioned that further experimental work is required for the validation of these findings.

\section{References}

[1] Abrams, D., Smith, T., Lynch J., and Franklin, S. Effectiveness of Rehabilitation on. Seismic Behaviour of Masonry Piers. ASCE Journal of Structural. Enginering. 2007; 133(1), 32-44.

[2] Galati, N., Tumialan, G., and Nanni, A. (2006), "Strengthening with FRP bars of URM walls subject to out-of-plane loads." Construction and Building Materials. 2006; 20(1-2): 101-110.

[3] Mosallam, A. Out-of-plane flexural behavior of unreinforced red brick walls strengthened with FRP composites. Composites: Part B. 2007; 38: 559-574.

[4] Roca, P., Araiza, G. Shear response of brick masonry small assemblages strengthened with bonded FRP laminates for in-plane reinforcement. Construction and Building Materials. 2010; 24, 1372-1384.

[5] Lampropoulos, A., Paschalis, S., and Dritsos, S. RC versus UHPFRC jackets for the seismic upgrade of columns. IABSE Conference - Structural Engineering: Providing Solutions to Global Challenges, Geneva, Switzerland, 2015a.

[6] Lampropoulos, A., Paschalis, S., Tsioulou, O., and Dritsos, S. Strengthening of reinforced concrete beams using Ultra High Performance Fibre Reinforced Concrete. 4th International Conference on Concrete Repair, Rehabilitation and Retrofitting (ICCRRR 2015). Leipzig, Germany, 2015b.

[7] Lampropoulos, A., Paschalis, S., Tsioulou, O., and Dritsos, S. Strengthening of reinforced concrete beams using ultra high performance fibre reinforced concrete (UHPFRC). Engineering Structures. 2016a; 106: 370-384.

[8] Lampropoulos, A., Tsioulou O., Paschalis S., and Dritsos, S. Strengthening of unreinforced masonry structures using Ultra High Performance Fibre Reinforced Concrete (UHPFRC). 19 IABSE Congress, Stockholm, Sweden, 2016b.

[9] Somr, M. Numerical simulation of cocciopesto-based masonry structures. Diploma Thesis. Czech Technical University, Prague, Czech Republic, 2011.

[10]Cervenka, V., Jendele, L., and Cervenka, J. ATENA Program Documentation: Part 1 Theory. Prague, Czech Republic, 2013.

[11]Wang, J., Heath, A., and Walker, P. Numerical analysis of triplet shear test on brickwork masonry. $3^{\text {rd }}$ International Conference on Civil Engineering and Building Materials, Hong Kong, Chin, 2014. 